\title{
Effects of Tai Chi exercises on self-efficacy and psychological health
}

\author{
Arnaud Dechamps • Lucile Lafont • \\ Isabelle Bourdel-Marchasson
}

Received: 15 September 2006 / Accepted: 22 January 2007 / Published online: 14 February 2007

(C) EGREPA 2007

\begin{abstract}
This review offers an update of the psychological effects of Tai Chi Chuan (TC) among different populations. A computerized literature research from 1990 to June 2006 was carried out. Studies were selected when they assessed the mental and psychological effects of TC practice among various populations. Data from 14 studies for a total of 829 subjects, age range from 12 to 96 years, were considered here. There were eight randomized controlled trials and six quasi-experimental or case control studies in this review. The intensity of TC varied from 30 min twice a week over a 5 -week period to $1 \mathrm{~h}$ every day over an 8 -week period. TC was characterized as a kind of light-to-moderate exercise and was found to enhance overall psychological well-being and to improve self-efficacy and mood. TC benefits appeared to be more tangible for adults and healthy older adults or those becoming frail. However, TC did not appear to be more efficient than exercises of the same intensity. Extensive and qualitative studies are needed to quantify the
\end{abstract}

\author{
A. Dechamps $\cdot$ L. Lafont \\ Laboratoire VSTII EA 498, Faculté des Sciences du Sport, \\ Université Victor Segalen Bordeaux 2, \\ Bordeaux, France \\ I. Bourdel-Marchasson \\ Département de gériatrie, Hôpital Xavier Arnozan, \\ 33604 Pessac cedex, France \\ I. Bourdel-Marchasson $(\square)$ \\ UMR 5536 CNRS/Université Bordeaux 2, \\ 146 rue Léo Saignat, \\ 33000 Bordeaux, France \\ e-mail: isabelle.bourdel-marchasson@chu-bordeaux.fr \\ I. Bourdel-Marchasson \\ Centre de Gériatrie Henri Choussat, Hôpital Xavier-Arnozan, \\ CHU de Bordeaux, \\ Pessac 33604, France
}

effects of the volume of practice, expert modeling, gender differences, and the age-related learning process on efficacy cognitions and mood in clinical and nonclinical contexts.

Keywords Tai Chi Chuan · Self-efficacy $\cdot$ Well-being

\section{Introduction}

Despite the fact that physical activity is associated with a decrease in morbidity and several health benefits, few people at any age engage in daily physical activity $[1,2]$. Daily moderate physical activity is recommended to improve general health, as vigorous exercise is considered as a barrier to exercise among people with a sedentary lifestyle [1].

Tai Chi Chuan (TC) or Taiji is a traditional Chinese form of exercise based on martial arts. TC practice is a light-tomoderate intensity exercise [3,4]. The "Chuan" term is often omitted in the literature and means "boxing." Literally, TC means the supreme ultimate boxing or "Yin and Yang boxing." In the TC philosophy, Yin refers to shadow, soft and feminine, whereas Yang is the light, hard and masculine part [5]. TC boxing was codified between the Ming (1368-1644) and the beginning of the Quing dynasties (1644-1911). TC forms are characterized as slow circular controlled sequences of movements, which slightly differ between TC schools.

Physical exercise has a number of psychological benefits, such as reduction in mood disturbance, improvement of quality of life, well-being, and self-efficacy [6-8]. Studies $[9,10]$ have provided evidence that a psychological variable like self-efficacy predicts behavioral adhesion. Perceived self-efficacy refers to beliefs in one's capabilities to organize and execute the courses of action required to 
produce given attainments [11, p 2]. Moreover, among sedentary people, mental health, well-being, and outcome expectations may influence exercise adhesion $[10,12,13]$. The increasing number of TC practitioners and healthrelated publications calls for an update of the scientific evidence supporting psychological benefits and exercise adhesion related to TC practice. However, despite its popularity, the mental health effects of TC are still unclear [14]. The goals of this systematic review are (1) to review the body of literature assessing the health benefits of TC and (2) to provide a systematic critical analysis of the evidence based on the mental/psychological health effects of TC practice among different populations. The conclusions of this review may result in rehabilitation initiatives and new directions for research.

\section{Materials and methods}

\section{Literature research}

The literature research was conducted as a systematic search from January 1990 to June 2006 using electronic databases including: Ebsco Host, Wiley Interscience, Taylor \& Francis, Blackwell Publishing, PubMed, and Science Direct. Searches were limited by keywords: 'Tai Chi Chuan' or 'Taiji', 'mental health', 'self-efficacy', 'well-being', 'selfesteem', 'mood', and 'depression'. Then, titles and abstracts related to TC practice and mental/psychological health and well-being were preselected. Furthermore, a general perspective about TC health effects from previous reviews is included in this present review.

\section{Study selection}

Studies were assessed using the Scottish Intercollegiate Guidelines Network $50[15,16]$. Each paper identified as relevant was appraised independently by two reviewers. They agreed on a methodological quality rating using the methodology and hierarchy of study types published elsewhere $[15,16]$. The reviewers' agreement score measured using the formula $\frac{\text { agreement-disagreement }}{\text { number ofdecision }}$ was 0.98 . The hierarchy criteria are presented in Table 1 . Methodological quality was rated using published criteria $[15,16]$ presented in Table 2.

\section{Inclusion and exclusion criteria}

Studies were excluded for any of the following reasons: (1) if the principal aim of the study was not to assess the mental and psychological health effects of TC; (2) if intervention procedure and outcomes were not adequately described; (3) if no definition/description of TC exercises was provided.
Table 1 Level of evidence (with permission from the SIGN, from section 6 of the SIGN50, 2004) $[15,16]$

\section{Level of evidence}

A At least one meta-analysis, systematic review, or RCT rated as $1^{++}$, and directly applicable to the target population; or

A systematic review of RCTs or a body of evidence consisting, principally, of studies rated as $1^{+}$, directly applicable to the target population, and demonstrating overall consistency of results

B A body of evidence including studies rated $2^{++}$, directly applicable to the target population and demonstrating overall consistency of results; or Extrapolated evidence from studies rated as $1^{++}$or $1^{+}$

C A body of evidence including studies rated $2^{+}$, directly applicable to the target population and demonstrating overall consistency of results; or Extrapolated evidence from studies rated as $2^{++}$

D Evidence level 3 or 4; or Extrapolated evidence from studies rated as $2^{+}$

$R C T$ Randomized controlled trial

Inclusion criteria were studies with principal objective to assess the effect of TC practice on self-efficacy, well-being, and mental/psychological health.

\section{Results}

Overview of previous reviews

The historical perspective provided by examining previous reviews substantiates the conclusion about TC efficacy and

Table 2 Grades of recommendation (reproduced with the permission of the SIGN group)

Grades of recommendation

$1^{++}$High quality meta-analyses, systematic reviews of RCTs, or RCTs with a very low risk of bias

$1^{+}$Well conducted meta-analyses, systematic reviews of RCTs, or RCTs with a low risk of bias

$1^{-}$Meta-analyses, systematic reviews of RCTs, or RCTs with a high risk of bias

$2^{++}$High quality systematic reviews of case control or cohort or studies High quality case-control or cohort studies with a very low risk of confounding, bias, or chance and a high probability that the relationship is causal

$2^{+}$Well conducted case-control or cohort studies with a low risk of confounding, bias, or chance and a moderate probability that the relationship is causal

$2^{-}$Case control or cohort studies with a high risk of confounding, bias, or chance and a significant risk that the relationship is not causal

3 Nonanalytic studies, e.g., case reports, case series

RCT Randomized controlled trial 
directions for research being guided by emerging knowledge. A total of nine reviews from 2000 to 2006 were found [4, 14, 17-23], including more than 4,000 participants in 72 trials. Twenty were randomized controlled trials and 50 nonrandomized trials. On the whole, the main countries of origin of publications were China for $48.8 \%$, the USA, $41.7 \%$ followed by Australia and Canada. The nonrandomized studies mainly come from China.

The length of the studies $(n=72)$ varied from 1 to 156 weeks, the most reported intervention frequency being 12 weeks (15\% of trials) followed by 8 weeks $(10 \%$ of trials). The duration of TC practice varied from 5 to $90 \mathrm{~min}$ per session for one to six sessions a week. The most frequent duration/frequency was 60 min twice a week (18.5\% of trials). Most of the studies (40\%) used the traditional Yang style of 108 movements, whereas $15 \%$ of trials used a simplified form comprising between 5 and 24 movements.

The number of subjects varied from 1 to 256 for an age ranging between 21 and 92 . The minimal mean age was 50 for $76 \%$ of the studies $(n=72)$. At the gender level, the sex ratio was rarely reported; among $65 \%$ of trials with a mixed gender population, only $20 \%$ reported the sex ratio.

Reviews published between 2001 and 2006 suggest that TC practice provided health benefits among adults and elderly [17, 19, 21, 23]. Results from balance and postural control studies showed moderate evidence concerning the efficacy of TC on reduction in falls and improving postural control. Nevertheless, a significant reduction in fear of falling and an overall functional improvement were found $[18,20,22]$. On the other hand, none of the studies reviewed in these reviews assessed the effects of TC on institutionalized elders with or without cognitive impairments.

\section{Analysis of the psychological effects of Tai Chi practice}

Few studies have provided information about the psychological effects of TC, yet the relaxing and beneficial nature of TC exercise still requires clarification [14]. In light of the above review conclusions, two main aspects based on studies from 1990 to June 2006 are discussed here: (1) the relationship between psychological factors and adhesion; (2) TC expert guidance when the information is available, with the modeling approach serving as a reference [24]. A total of 67 references were obtained. Based on title and abstract, 20 articles were selected. Of these 20, three studies were rejected because the intervention was a combination of exercises, did not mainly comprise TC exercises, or was not clearly described, whereas three other studies were not included because psychological health was not the main outcome. Thus, details of 14 studies are presented according to study design in Tables 3 and 4 [3, 25-38]. A total of eight randomized controlled studies and six nonrandomized ones were, thus, considered in this analysis. A detailed analysis of four high quality trials is presented below.

Details of high quality trials

Brown et al. [37] studied the cognitive effects of exercise on psychological benefits. Out of a total of 163 sedentary healthy older adults (aged 40-69 years), 135 participants finished the intervention consisting of three sessions a week for 16 weeks. Participants were randomly assigned to one of the five experimental procedures: (1) moderate intensity walking (MW), 65-75\% of heart rate reserve (HRR), 30$40 \mathrm{~min}$; (2) low intensity walking (LW), 45-55\% of HRR, 40-50 min; (3) low intensity walking plus relaxation response (LWR, relaxation tape), 40-50 min; (4) mindful exercise (ME) Tai Chi exercises, $45 \mathrm{~min}$; (5) control. The $\mathrm{ME}$ group received instructions from an exercise leader, whereas the walking groups autonomously used an indoor walking track. The dependent measures for the psychological change were mood, self-esteem, life satisfaction, and personality inventories. The results showed that women in the ME group achieved a significant decrease in anger and total mood disturbances than those in the LW and LWR groups. Compared to the LW and LWR subjects, women in the ME group also showed a greater decrease in confusion, depression, and tension in the profile of mood states. For men, the MW procedure had more positive effects on mood than the other procedures, and all four procedures had more favorable effects at 16 weeks.

Li et al. [3] studied TC effects on self-efficacy and exercise adhesion. Low-active and independent older adults ( $n=98)$, 65-96 years old (mean $73.2 \pm 4.91$ year) were randomly assigned to two groups, TC or control (waiting list for TC course after the trial). Participants in the TC procedure followed a 6-month program of $60 \mathrm{~min}$ of $\mathrm{TC}$ Yang (24 movements) twice a week. Cognitive functions were not assessed either before or after the intervention. During the TC course, participants were instructed to replicate the motions, postures, and movement at the speed of the instructor. No information was given concerning the effect of age on the time to learn the TC forms. Dependent measures were exercise barriers and performance selfefficacy. Class attendance was also recorded as an exercisebehavior outcome. Results showed a general improvement in TC exercise self-efficacy. Class compliance was predicted by both dimensions of self-efficacy. Regression coefficients of barriers and performance efficacy suggested that exercise adherence was significantly related to self-efficacy cognitions [3].

Two trials from the Atlanta Frailty and Injuries: Cooperative Studies on Intervention Techniques (FICSIT) examined the psychosocial and health effects of TC practice $[33,35]$. Subjects $(n=200)$ with a mean age of 76.2 years of 


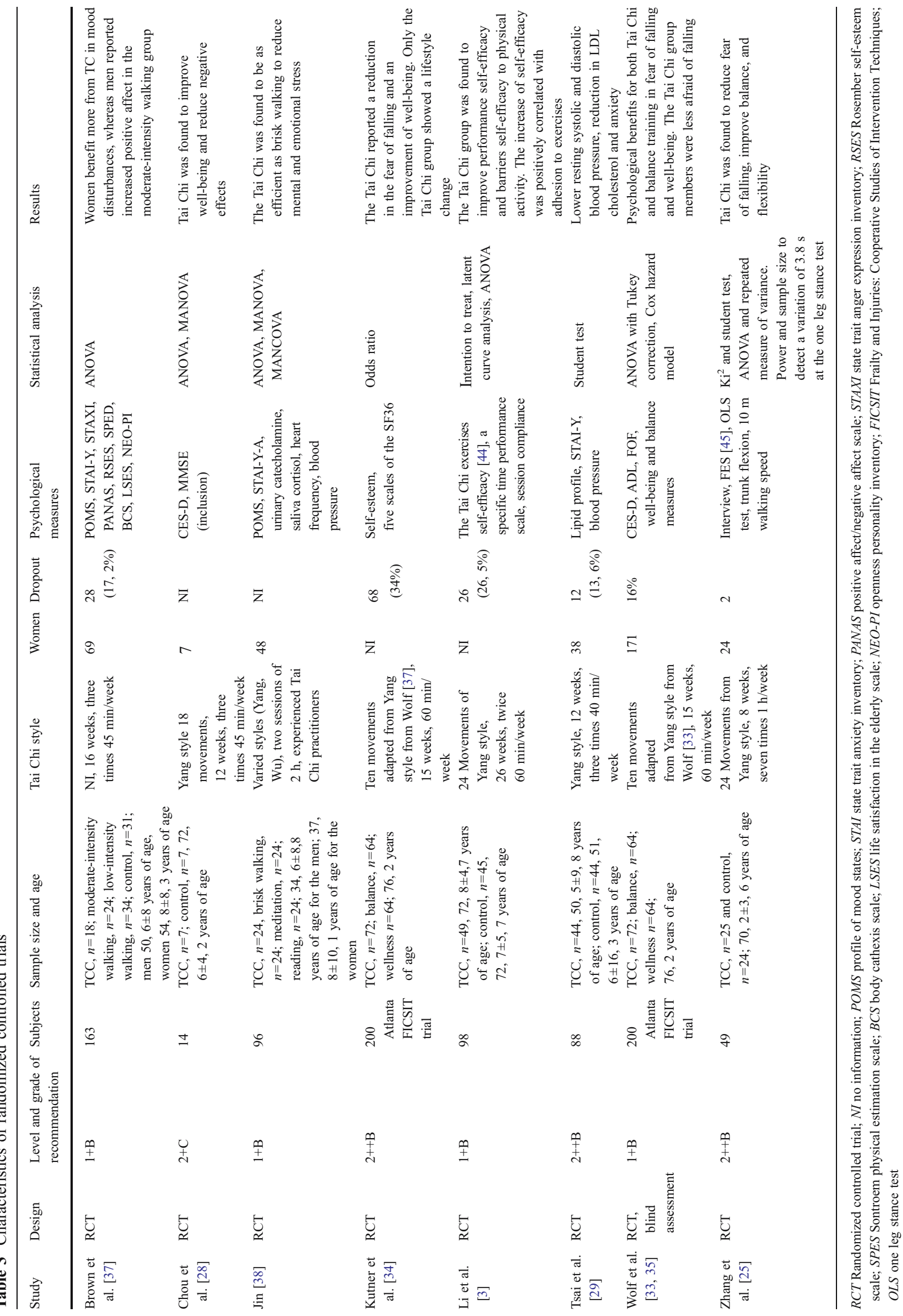




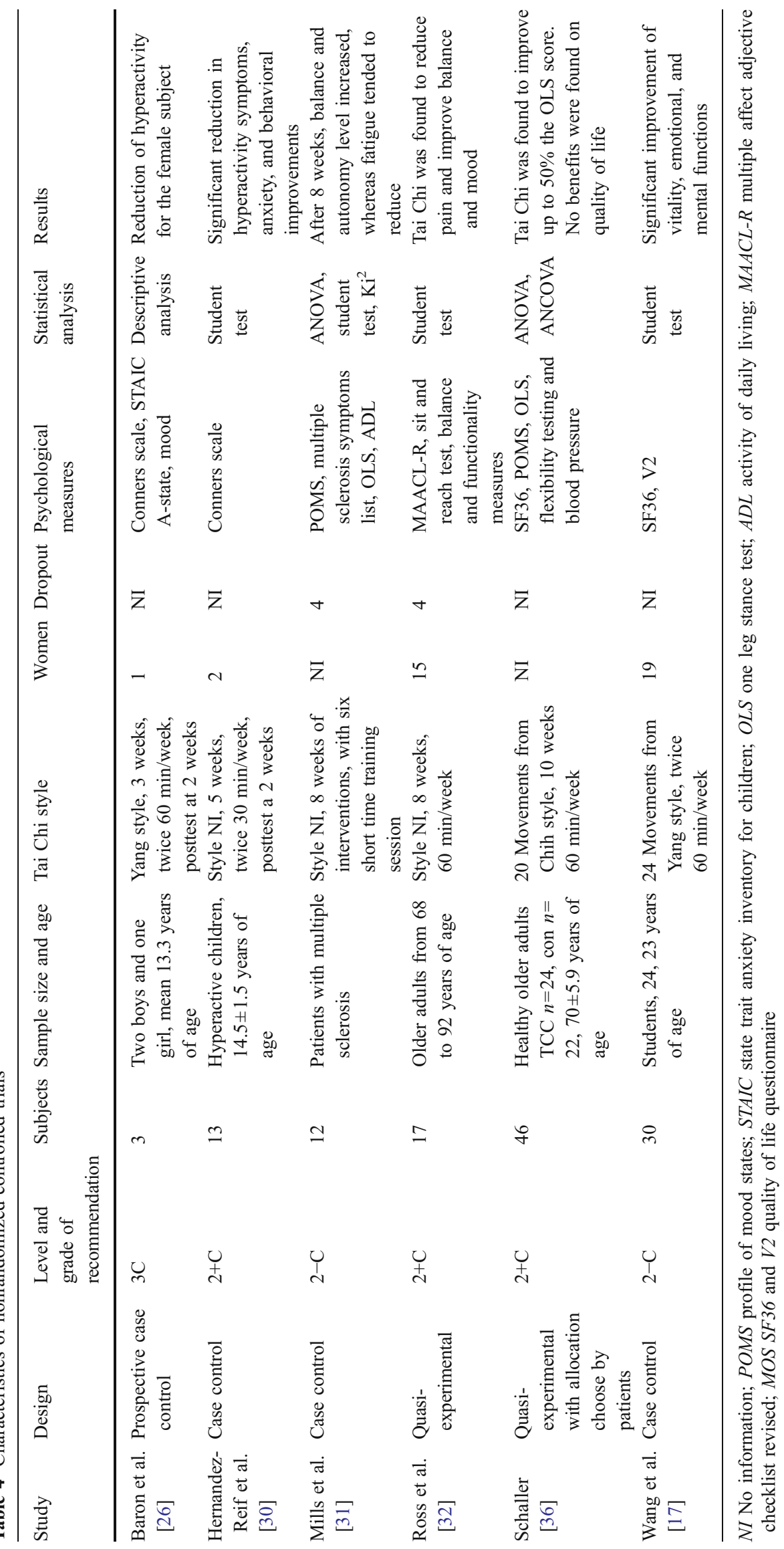


age were independent and community living. They were randomly assigned to one of the three groups: a 15-week course of TC Yang style $(n=72)$, computerized balance training $(n=64)$, or education $(n=64)$. Subjects with severe cognitive impairments (not defined) or Parkinson's disease were excluded. The TC group met twice weekly, and the balance training and control groups met once weekly. The practitioners reproduced the motions and speed of the movements from the expert demonstrations. No information was given for the time needed to learn the TC form. It was found that those who participated in TC had a $48 \%$ reduction in the risk of falls, reduced their fear of falling, and improved their well-being. A trend of a higher increase in self-efficacy and overall improvement was found in favor of the TC group, but this was not statistically significant.

\section{Commentary}

The majority of the randomized controlled studies reviewed here concerned TC benefits in adults aged 55 and older. This is also among such population that research has shown tangible results. Few nonrandomized studies have targeted TC effects on younger and middle-aged people [26, 27, 30]. However, the effects noted should be interpreted cautiously considering the lack of information on the description of the experimental settings and interventions used. For some authors, the intensity component of exercise could mediate adhesion [3, 31, 37]. People who do not like intense exercise or the deconditioned ones might benefit more from TC exercise [4, 26, 37, 38].

Analyses according to gender have been almost entirely absent from TC research. One study [37] that did investigate gender differences demonstrated that men may benefit more from walking exercises in terms of mood improvements, whereas this effect was observed after TC practice in women.

The majority of studies have described the psychological benefits of TC practice. Time is an important factor in physical and psychological interventions. The length of studies varied from 5 to 26 weeks, so the long-term effects of TC practice are still unknown. The relationship between length and frequency of exercise and psychological effects was not addressed in most of the studies. Moreover, as TC is classified as a form of moderate intensity exercise [4], it is important to take into account public health recommendations about exercise [1]. In the present review, one study used an intervention procedure according to the recommendations [25]. In addition, a dose/response effect of exercise on mood has recently been demonstrated [39, 40]. Tsang et al. [41] showed a positive relation between length and the frequency of TC practice on balance, which could explain most of the inconsistency found in studies where there were few sessions per week.
An effect of incorporation of TC activity on patients' lifestyle after the intervention has also been found [34, 37], underlining the need for further investigation into the adhesion mechanisms related to TC practice. Besides the effects of the intervention length and the volume of practice, the role of the expert guidance and the conditions in which the TC training are given should be taken into account when assessing its beneficial effects.

Studies that directly compared TC with other forms of exercise undertaken at the same intensity are not numerous $[33,35,37,38]$. Others $[3,25,27-30,32-35,37,38]$ have shown beneficial effects of TC practice on mood, wellbeing, self-efficacy, and exercise participation. However, the results observed in TC practice were not statistically significant compared to other exercises of equivalent intensity. In addition, studies comparing TC with other forms of exercise need equivalence testing in terms of intensity, volume, and length of training.

To date, only three studies have used blind outcome assessment to prevent performance and detection, including two from the Atlanta FICSIT trial bias [33, 35, 38]. However, blinding was not mentioned as a method to prevent bias, so it is not clear whether or not the authors tried to keep the patients, caregivers, or the outcome assessors unaware of the intervention procedures.

The conditions in which TC learning is conducted need further examination, as a number of studies relied on grossly different styles and forms of TC. When a sequence of movements has to be learned by heart, focusing on the exact movement form may be a disadvantage for people with learning disabilities, spatial perception problems, or cognitive impairments. As no information was given with regard to older adults' learning difficulties, it is not possible to draw any firm conclusions about the cognitive benefits of TC practice. In addition, the mind-body effects of TC exercise could be an adjustment between cognition and action during TC practice. This may be enhanced via qualitative components from the instructor's experience and personality and are quasi-absent in Western rehabilitation programs $[4,42,43]$. The procedure and the guidance used by the TC expert could account for most of the results [26, 30-32]. As TC intervention relies on qualitative components (imagery, philosophy, TC principles, etc.), it is likely that the expert's guidance and his personality are mediators of adhesion [26, 31, 32]. Both the improvement and perception of control of our own health also mediate participation and adhesion to exercise prescription [3, 31, 37]. For these reasons, more studies are needed to assess the qualitative components of expert guidance on mood improvement.

Finally, there is no formal evidence that TC is more beneficial than other forms of exercise of the same intensity. At the psychological level and in terms of quality 
of life, practice through its philosophical and aesthetic aspects would seem to have some beneficial effects, which in turn might be more marked in populations educated to high school level and beyond [33, 35, 37]. Moreover, no gender effects on mood, self-efficacy, outcome expectations, and well-being have been reported to date, yet some data [37] suggest that gender might be a moderator.

These conclusions should be taken with caution, as the literature searches were in English and French, so most of the Chinese studies were not reviewed here. However, a large systematic review of Chinese studies has been performed by others [17].

\section{Conclusion}

$\mathrm{TC}$ is a form of risk-free exercise suitable for people unsuited to high intensity physical activity. The movements of TC might therefore be the thrust of future interventions in populations with a sedentary lifestyle or the elderly. Our conclusions confirm those of Sandlund and Norlander [14]. They stated that the beneficial effects reported in TC practice need further investigations about the time needed to learn the techniques, the learning procedures, and the perception of the activity from the subject's point of view. Moreover, as the intervention procedure and the expert guidance are mediators, more extensive studies are required on this issue.

\section{References}

1. US Public Health Service, Office of the Surgeon General, National Center for Chronic Disease Prevention and Health Promotion (1996) President's Council on Physical Fitness and Sports. Physical activity and health: a report of the Surgeon General. Atlanta, GA, xvii, p 278

2. American Geriatrics Society, British Geriatrics Society, American Academy of Orthopaedic Surgeons Panel on Falls Prevention (2001) Guideline for the prevention of falls in older persons. J Am Geriatr Soc 49(5):664-672

3. Li F, Harmer P, McAuley E, Fisher KJ, Duncan TE, Duncan SC (2001) Tai Chi, self-efficacy, and physical function in the elderly. Prev Sci 2(4):229-239

4. Taylor-Piliae RE, Froelicher ES (2004) Effectiveness of Tai Chi exercise in improving aerobic capacity: a meta-analysis. J Cardiovasc Nurs 19(1):48-57

5. Despeux C (1981) Taiji Quan: art martial, technique de longue vie. Guy Trédaniel, Paris p 316

6. Babyak M, Blumenthal JA, Herman S, Khatri P, Doraiswamy M, Moore K, Craighead WE, Baldewicz TT, Krishnan KR (2000) Exercise treatment for major depression: maintenance of therapeutic benefit at 10 months. Psychosom Med 62(5):633-638

7. Craft LL, Perna FM (2004) The benefits of exercise for the clinically depressed. Primary care companion. J Clin Psychiatry 6(3):104-111
8. US Public Health Service, Office of the Surgeon General (1999) Mental health: a report of the Surgeon General. Dept. of Health and Human Services, US Public Health Service, (Rockville, Md.) Pittsburgh, PA, xvi, p 487, for sale by the Supt. of Docs

9. Bandura A (2004) Health promotion by social cognitive means. Health Educ Behav 31(2):143-164

10. Cress ME, Buchner DM, Prohaska T, Rimmer J, Brown M, Macera C, DePietro L, Chodzko-Zajko W (2006) Best practices for physical activity programs and behavior counseling in older adult populations. Eur Rev Aging Phys Act 3(1):34-42

11. Bandura A (1997) Self-efficacy: the exercise of control. Freeman, New York, ix, p 604

12. Bandura A (2005) The primacy of self-regulation in health promotion. Appl Psychol 54(2):245-254, an international review

13. Schwarzer R (1992) Self-efficacy in the adoption and maintenance of health behaviors: theoretical approaches and a new model. Selfefficacy: thought control of action. Hemisphere, Washington, pp 217-242

14. Sandlund ES, Norlander T (2000) The effects of Tai Chi Chuan relaxation and exercise on stress responses and well-being: an overview of research. Int J Stress Manag 7(2):139-149

15. Harbour R, Miller J (2001) A new system for grading recommendations in evidence based guidelines. BMJ 323(7308):334-336

16. SIGN (2004) SIGN 50: a guideline developer's handbook. Scottish Intercollegiate Guidelines Network. http://www.sign.ac. uk/guidelines/fulltext/50/index/html

17. Wang C, Collet JP, Lau J (2004) The effect of Tai Chi on health outcomes in patients with chronic conditions: a systematic review. Arch Intern Med 164(5):493-501

18. Wayne PM, Krebs DE, Wolf SL, Gill-Body KM, Scarborough DM, McGibbon CA, Kaptchuk TJ, Parker SW (2004) Can Tai Chi improve vestibulopathic postural control? Arch Phys Med Rehabil 85(1):142-152

19. Verhagen AP, Immink M, van der Meulen A, Bierma-Zeinstra SM (2004) The efficacy of Tai Chi Chuan in older adults: a systematic review. Fam Pract 21(1):107-113

20. Wu G (2002) Evaluation of the effectiveness of Tai Chi for improving balance and preventing falls in the older population-a review. J Am Geriatr Soc 50(4):746-754

21. Klein PJ, Adams WD (2004) Comprehensive therapeutic benefits of Taiji: a critical review. Am J Phys Med Rehabil 83(9):735-745

22. Komagata S, Newton R (2003) The effectiveness of Tai Chi on improving balance in older adults: an evidence-based review. J Geriatr Phys Therf 26(2):9-16

23. Li JX, Hong Y, Chan KM (2001) Tai chi: physiological characteristics and beneficial effects on health. Br J Sports Med 35(3):148-156

24. Bandura A (1986) Social foundations of thought and action: a social cognitive theory, xiii. Prentice-Hall, Englewood Cliffs, NJ, p 617

25. Zhang JG, Ishikawa-Takata $\mathrm{K}$, Yamazaki $\mathrm{H}$, Morita $\mathrm{T}$, Ohta $\mathrm{T}$ (2006) The effects of Tai Chi Chuan on physiological function and fear of falling in the less robust elderly: An intervention study for preventing falls. Arch Gerontol Geriatr 42(2):107-116

26. Baron LJ, Faubert C (2005) The role of Tai Chi Chuan in reducing state anxiety and enhancing mood of children with special needs. J Bodyw Mov Ther 9(1):120-133

27. Wang YT, Taylor L, Pearl M, Chang LS (2004) Effects of Tai Chi exercise on physical and mental health of college students. Am J Chin Med 32(3):453-459

28. Chou KL, Lee PW, Yu EC, Macfarlane D, Cheng YH, Chan SS, Chi I (2004) Effect of Tai Chi on depressive symptoms amongst Chinese older patients with depressive disorders: a randomized clinical trial. Int J Geriatr Psychiatry 19(11):1105-1107

29. Tsai JC, Wang WH, Chan P, Lin LJ, Wang CH, Tomlinson B, Hsieh MH, Yang HY, Liu JC (2003) The beneficial effects of Tai Chi Chuan on blood pressure and lipid profile and anxiety status 
in a randomized controlled trial. J Altern Complement Med 9(5):747-754

30. Hernandez-Reif M, Field TM, Thimas E (2001) Attention deficit hyperactivity disorder: benefits from Tai Chi. J Bodyw Mov Ther 5(2): $120-123$

31. Mills N, Allen J, Carey-Morgan S (2000) Does Tai Chi/Qi Gong help patients with Multiple Sclerosis? J Bodyw Mov Ther 4(1):39-48

32. Ross MC, Bohannon AS, Davis DC, Gurchiek L (1999) The effects of a short-term exercise program on movement, pain, and mood in the elderly. Results of a pilot study. J Holist Nurs 17(2):139-147

33. Wolf SL, Barnhart HX, Ellison GL, Coogler CE (1997) The effect of Tai Chi Quan and computerized balance training on postural stability in older subjects. Atlanta FICSIT Group. Frailty and Injuries: Cooperative Studies on Intervention Techniques. Phys Ther 77(4):371-381, discussion 382-384

34. Kutner NG, Barnhart H, Wolf SL, McNeely E, Xu T (1997) Selfreport benefits of Tai Chi practice by older adults. J Gerontol B Psychol Sci Soc Sci 52(5):P242-P246

35. Wolf SL, Barnhart HX, Kutner NG, McNeely E, Coogler C, Xu T (1996) Reducing frailty and falls in older persons: an investigation of Tai Chi and computerized balance training. Atlanta FICSIT Group. Frailty and Injuries: Cooperative Studies of Intervention Techniques. J Am Geriatr Soc 44(5):489-497

36. Schaller KJ (1996) Tai Chi Chih: an exercise option for older adults. J Gerontol Nurs 22(10):12-17

37. Brown DR, Wang Y, Ward A, Ebbeling CB, Fortlage L, Puleo E, Benson H, Rippe JM (1995) Chronic psychological effects of exercise and exercise plus cognitive strategies. Med Sci Sports Exerc 27(5):765-775

38. Jin P (1992) Efficacy of Tai Chi, brisk walking, meditation, and reading in reducing mental and emotional stress. J Psychosom Res 36(4):361-370

39. Blumenthal JA, Babyak MA, Moore KA, Craighead WE, Herman S, Khatri P, Waugh R, Napolitano MA, Forman LM, Appelbaum M et al (1999) Effects of exercise training on older patients with major depression. Arch Intern Med (Baltimore) 159(19):2349-2356

40. Dunn AL, Trivedi MH, Kampert JB, Clark CG, Chambliss HO (2005) Exercise treatment for depression: efficacy and dose response. Am J Prev Med 28(1):1-8

41. Tsang WW, Hui-Chan CW (2004) Effect of 4- and 8-wk intensive Tai Chi Training on balance control in the elderly. Med Sci Sports Exerc 36(4):648-657

42. Jancewicz A (2001) Tai Chi Chuan's role in maintaining independence in ageing people with chronic disease. J Bodyw Mov Ther 5(1):70-77

43. Taylor-Piliae RE (2003) Tai Chi as an adjunct to cardiac rehabilitation exercise training. J Cardiopulm Rehabil 23(2): 90-96

44. McAuley E, Mihalko SL (1998) Measuring exercise-related selfefficacy. In: Duda JJ (ed). Advancements in sport and exercise psychology measurement. Morgantown: WV, pp 371-390

45. Tinetti ME, Richman D, Powell L (1990) Falls efficacy as a measure of fear of falling. J Gerontol 45(6):239-243 